Jurnal Ilmiah Matematika dan Pendidikan Matematika (JMP)

Vol. 9 No. 2, Desember 2017, hal. 37-48

ISSN (Cetak) : 2085-1456; ISSN (Online) : 2550-0422; https://jmpunsoed.com/

\title{
KLASIFIKASI KARAKTERISTIK KONSUMEN \\ SEPEDA MOTOR MERK T DI JAWA BARAT MENGGUNAKAN \\ METODE NAÏVE BAYES CLASSIFIER PADA DATA MINING
}

\author{
Jaka Aulia Pratama \\ Departemen Statistika, Universitas Padjadjaran \\ jakajek@gmail.com \\ Zulhanif \\ Departemen Statistika, Universitas Padjadjaran \\ Yadi Suprijadi \\ Departemen Statistika, Universitas Padjadjaran
}

\begin{abstract}
PT. JKL has a role as a main dealer of T's brand are handling three types of motorcycle products in West Java. These are type of Sport, CUB, and Scooter (Automatic Transmissions). The company records the buyer of T's brand motorcycle in the Customer Database (CDB). CDB collected from 2011 to 2013 yielded information of consumer characteristics which is necessary in market planning. Consumer characteristics are classified into two groups: Repeated Order and New Customer. Classification methods used in the study of Data Mining is the Naïve Bayes Classifier. Model classification is done by calculating the conditional probability to choose the greatest value of probability. The accuracy of the classification is $83 \%$ and the error classification is $17 \%$.
\end{abstract}

Keywords: Database, Data Mining, Classification, Nä̈ve Bayes Classifier, Conditional Probability

ABSTRAK. PT. JKL berperan sebagai main dealer sepeda motor merk T menangani tiga jenis produk sepeda motor yaitu jenis Sport, CUB (Bebek), dan Skuter (Matic) di Jawa Barat. Perusahaan ini mencatat konsumen yang membeli produk sepeda motor merk $\mathrm{T}$ dalam Customer Database (CDB). CDB yang dihimpun dari tahun 2011 sampai dengan tahun 2013 menghasilkan informasi karakteristik konsumen yang diperlukan dalam perencanaan pemasaran. Karakteristik konsumen diklasifikasikan menjadi dua yaitu Repeat Order dan New Customer. Metode klasifikasi yang digunakan dalam penelitian Data Mining ini adalah Nä̈ve Bayes Classifier. Model pengklasifikasian dilakukan dengan cara menghitung peluang bersyarat dengan memilih nilai peluang yang paling besar. Ketepatan dalam klasifikasi adalah sebesar $83 \%$ dan kesalahan klasifikasi adalah sebesar $17 \%$.

Kata Kunci: Database, Data Mining, Klasifikasi, Nä̈ve Bayes Classifier, Peluang Bersyarat 


\section{PENDAHULUAN}

PT. JKL adalah perusahaan yang bergerak dalam bidang distribusi sepeda motor dan suku cadang sepeda motor merk $\mathrm{T}$ yang menangani tiga jenis produk sepeda motor yaitu jenis Sport, CUB (Bebek), dan AT (Automatic) di 18 area dealer-dealer cabang di Jawa Barat. PT. JKL mencatat data konsumen yang membeli produk sepeda motor merk $\mathrm{T}$ dalam database yang selanjutnya dinamakan Customer Database (CDB). Salah satu pemanfaatan Customer Database yaitu untuk menghasilkan informasi atau pengetahuan mengenai karakteristik konsumen sepeda motor merk T yang selanjutnya sangat diperlukan dalam rencana pemasaran. Karakteristik tersebut akan bermanfaat jika berlandaskan kepada hasil pengklasifikasian terhadap karakteristik konsumen Repeat Order dan New Customer. Untuk mendapatkan informasi dari Customer Database yang menunjukkan apakah konsumen tersebut Repeat Order atau New Customer, dapat dilihat dari merk sepeda motor yang dimiliki sebelumnya. Dalam Customer Database karakteristik kepemilikan sepeda motor sebelumnya dibagi menjadi merk T, merk A, merk motor lain, merk B, merk $\mathrm{C}$ dan belum pernah memiliki. Konsumen dengan merk sepeda motor yang dimiliki sebelumnya adalah merk T disebut sebagai konsumen dengan karakteristik Repeat Order, sedangkan konsumen dengan karakteristik kepemilikan sepeda motor bukan merk $\mathrm{T}$ dan belum pernah memiliki sepeda motor merupakan konsumen dengan karakteristik New Customer. Persentase kepemilikan sepeda motor sebelumnya dari konsumen PT. JKL tahun 2011 - 2013 ditunjukan pada Gambar 1.

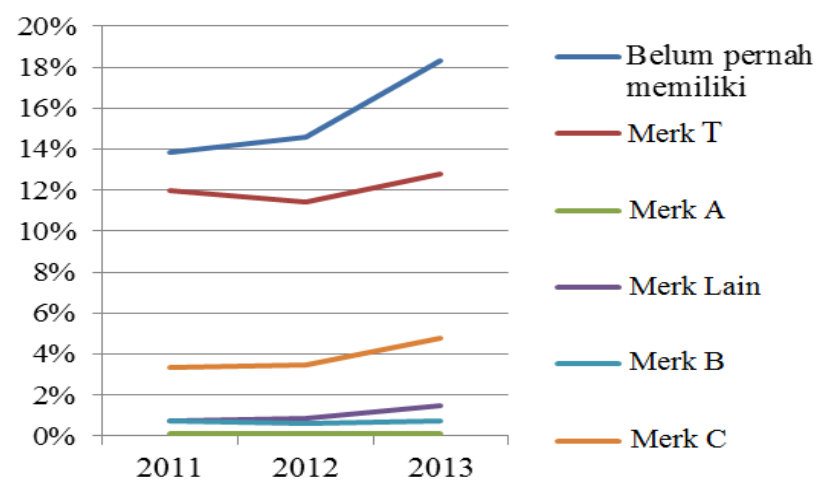

Gambar 1. Persentase Berdasarkan Kategori Kepemilikan Sepeda Motor Sebelumnya Konsumen PT. JKL tahun 2011-2013 
Gambar 1 menunjukkan bahwa tahun 2011 - 2013 konsumen dengan kepemilikan sepeda motor sebelumnya merk $\mathrm{T}$ dan konsumen yang belum pernah memiliki sepeda motor menjadi pangsa pasar utama PT. JKL, sedangkan persentase dari konsumen dengan kepemilikan sepeda motor sebelumnya merk C, merk motor lain, merk B dan merk A termasuk rendah yaitu dibawah $6 \%$ dari total penjualan selama tiga tahun tersebut. Oleh karena itu diperlukan strategi pemasaran melalui klasifikasi karakteristik konsumennya yang akan diambil dari Customer Database tahun 2011 - 2013.

Salah satu bahan yang diperlukan dalam membuat strategi pemasaran adalah klasifikasi karakteristik konsumen Repeat Order dan New Customer sepeda motor merk $\mathrm{T}$. Oleh karena itu yang menjadi permasalahan dalam penelitian ini adalah, bagaimana membuat klasifikasi tersebut dengan melibatkan nilai peluang pada setiap klasifikasinya apabila data yang akan diolah memiliki volume yang besar dan tersimpan dalam database.

Tujuan dari penelitian ini adalah, mengaplikasikan teknik Data Mining dalam pengklasifikasian dengan metode Nä̈ve Bayesian Classifier pada Customer Database PT. JKL. Hasil penelitian berupa klasifikasi karakteristik konsumen Repeat Order dan New Customer sepeda motor merk T di Jawa Barat diharapkan dapat membantu PT. JKL dalam menyusun strategi pemasaran yang lebih efektif kepada calon konsumen sepeda motor merk T di Jawa Barat.

\section{METODE PENELITIAN}

\subsection{Data Mining}

Data Mining adalah proses seleksi, eksplorasi, dan pemodelan data dalam jumlah besar untuk menemukan pola atau relasi yang ada dengan tujuan memperoleh hasil yang jelas dan berguna bagi pemilik database (Giudici, 2003). Pada Data Mining, terdapat dua pendekatan yang digunakan yaitu pedekatan statistika klasik dan metode kecerdasan buatan. Pendekatan statistika klasik yang dimaksud adalah data dieksplorasi dan dianalisis melalui metode-metode statistika. 
Pada umumnya, Data Mining digunakan untuk tujuan perdiksi dan deteksi. Prediksi tidak dipergunakan dalam tugas Data Mining pada penelitian ini karena tujuan dari penelitian ini bukan untuk melakukan peramalan yang umumnya menggunakan regresi demikian pula dengan asosiasi yang pada umumnya diaplikasikan dalam hal penentuan antar hubungan. Penelitian ini juga tidak mempunyai tujuan untuk mendeteksi kejadian yang tidak biasa (deteksi). Permasalahan dalam penelitian ini adalah menelaah karakteristik konsumen yang dapat digolongkan kepada kategori persoalan klasifikasi.

\subsection{Nä̈ve Bayes Classifier}

Nä̈ve Bayes Classifier adalah metode klasifikasi dalam Data Mining berdasarkan probabilitas dan teorema Bayes, dengan asumsi bahwa setiap variabel bersifat bebas (independent). Asumsi tersebut akan menghilangkan kebutuhan banyaknya jumlah data latih (Training Data) dari perkalian Kartesius seluruh variabel yang dibutuhkan untuk mengklasifikasikan suatu data (Berson dkk., 2001). Pada artikelnya Domingos dan Pazzani (1997) dijelaskan performa Nä̈ve Bayes Classifier dalam fungsi zero-one loss yaitu fungsi yang mendefinisikan error hanya sebagai pengklasifikasian yang salah. Tidak seperti fungsi error yang lain misalnya squared error, fungsi zero-one loss tidak memberi nilai suatu kesalahan perhitungan peluang selama peluang maksimum ditugaskan ke dalam kelas yang benar. Ini berarti bahwa Nä̈ve Bayes Classifier dapat mengubah peluang posterior dari tiap kelas, tetapi kelas dengan nilai peluang posterior maksimum jarang diubah. Berikut adalah algoritma Nä̈ve Bayes Classifier dengan asumsi semua atribut independen:

$$
\begin{aligned}
P\left(X_{1}, X_{2}, \cdots, X_{n} \mid Y\right) & =P\left(X_{1} \mid X_{2}, \cdots, X_{n}, C\right) P\left(X_{2}, \cdots, X_{n} \mid Y\right) \\
& =P\left(X_{1} \mid C\right) P\left(X_{2}, \cdots, X_{n} \mid Y\right) \\
& =P\left(X_{1} \mid C\right) P\left(X_{2} \mid C\right) \cdots P\left(X_{n} \mid Y\right)
\end{aligned}
$$

\subsection{Penurunan Algoritma Nä̈ve Bayes}

Menurut Mitchell (2010), algoritma Nä̈ve Bayes merupakan algoritma klasifikasi yang didasarkan pada aturan Bayes. Asumsi yang dipergunakan adalah 
bahwa atribut $X_{1}, \ldots X_{n}$ independen satu dengan yang lainnya yang diberikan oleh $Y$. apabila diberikan $X=\left(X_{1}, X_{2}, X_{3}\right)$, maka langkah untuk mengestimasi $P(X \mid Y)$ adalah sebagai berikut:

$$
\begin{aligned}
P(X \mid Y) & =P\left(X_{1}, X_{2}, X_{3} \mid Y\right) \\
& =P\left(X_{1} \mid Y\right) P\left(X_{2} \mid Y, X_{1}\right) P\left(X_{3} \mid Y, X_{1}, X_{2}\right)
\end{aligned}
$$

Menurut Novita (2014), karena asumsi independen bersyarat memegang peranan maka dianggap bahwa untuk setiap atribut $X_{i}$ terkondisi saling independen terhadap setiap atribut $X_{j}$ untuk $i \neq j$. Apabila asumsi independen bersyarat dipergunakan, maka Persamaan (2) dapat dituliskan menjadi:

$$
P\left(X_{1}, X_{2}, X_{3} \mid Y\right)=P\left(X_{1} \mid Y\right) P\left(X_{2} \mid Y\right) P\left(X_{3} \mid Y\right)
$$

Apabila $X$ mengandung $\mathrm{n}$ atribut yang bersifat independen bersyarat antara satu dengan lainnya yang diberikan oleh $Y$, secara umum dapat dituliskan sebagai berikut:

$$
P\left(X_{1}, \ldots, X_{n} \mid Y\right)=\prod_{i=1}^{n} P\left(X_{i} \mid Y\right)
$$

Secara umum, $X_{1}, \ldots X_{n}$ dan $Y$ adalah variable diskrit. Tujuan dari metode ini adalah untuk melatih sebuah classifier yang akan menghasilkan output berupa probabilitas atas kemungkinan nilai $Y$, untuk setiap $X$ baru yang akan diklasifikasikan. Pernyataan untuk peluang $Y$ akan diambil nilai ke- $k$ yang mungkin sesuai dengan aturan Bayes, dapat dituliskan sebagai berikut:

$$
P\left(Y=y_{k} \mid X_{1}, \ldots, X_{n}\right)=\frac{P\left(Y=y_{k}\right) P\left(X_{1}, \ldots, X_{n} \mid Y=y_{k}\right)}{\sum_{j} P\left(Y=y_{j}\right) P\left(X_{1}, \ldots, X_{n} \mid Y=y_{j}\right)}
$$

Pada penyebut terlihat bahwa jumlah yang dimaksud adalah pengambilan setiap nilai $y_{j}$ dari $Y$. apabila diasumsikan bahwa untuk setiap atribut $X_{i}$ adalah independen bersyarat yang diberikan oleh $Y$, Persamaan (5) dapat ditulis kembali sebagai berikut:

$$
P\left(Y=y_{k} \mid X_{1}, \ldots, X_{n}\right)=\frac{P\left(Y=y_{k}\right) \prod_{i=1}^{n} P\left(X_{i} \mid Y=y_{k}\right)}{\sum_{j} P\left(Y=y_{j}\right) \prod_{i=1}^{n} P\left(X_{i} \mid Y=y_{j}\right)}
$$


Persamaan (6) merupakan persamaan dasar untuk metode Nä̈ve Bayes. Menurut Novita (2014) apabila diberikan nilai $X^{\prime}=\left(X_{1}, \ldots X_{n}\right)$ yang baru, persamaan tersebut menunjukkan bagaimana cara untuk menghitung probabilitas bahwa $Y$ akan terjadi untuk setiap atribut $X^{\prime}$ dan diberikan distribusi $P(Y)$ dan $P\left(X_{i} \mid Y\right)$ yang diestimasi berdasarkan data training. Dalam menentukan peluang $X^{\prime}$ menjadi kategori dari kelas $Y$, maka aturan klasifikasi dalam Nä̈ve Bayes dapat dituliskan sebagai berikut:

$$
Y \leftarrow \arg \max _{y k} \frac{P\left(Y=y_{k}\right) \prod_{i=1}^{n} P\left(X_{i} \mid Y=y_{k}\right)}{\sum_{j} P\left(Y=y_{j}\right) \prod_{i=1}^{n} P\left(X_{i} \mid Y=y_{j}\right)}
$$

Aturan keputusan dalam klasifikasi Nä̈ve Bayes sering disebut dengan aturan keputusan Maximum A Posteriori (MAP) karena pada saat klasifikasi, pendekatan Bayes akan menghasilkan label kategori yang paling tinggi probabilitasnya. Pada Persamaan (7) terlihat bahwa penyebut tidak bergantung pada $y_{k}$, maka Persamaan (7) dapat disederhanakan menjadi:

$$
Y \leftarrow \arg \max _{y k} P\left(Y=y_{k}\right) \prod_{i=1}^{n} P\left(X_{i} \mid Y=y_{k}\right)
$$

\subsection{Ketepatan Klasifikasi}

Pada penelitian ini, ketepatan klasifikasi diukur oleh Apparent Error Rate (APER). Untuk menghitung nilai APER beberapa prosedur menyarankan untuk membagi total sampel yang digunakan kedalam dua kelompok, yaitu Analysis Sample (Data Training) dan Holdout Sample (Data Testing). Pada kelompok Analysis Sample digunakan untuk membuat model klasifikasi, sedangkan pada kelompok Holdout Sample digunakan untuk menguji ketepatan klasifikasi yang dilakukan (Hair, et al, 1998).

APER dihitung dengan terlebih dahulu dengan membuat tabel klasifikasi seperti pada Tabel 1: 
Tabel 1. Klasifikasi Untuk Actual Group dan Predicted Group

\begin{tabular}{|c|c|c|}
\hline \multirow{2}{*}{ Actual Group } & \multicolumn{2}{|c|}{ Predicted Group } \\
\cline { 2 - 3 } & $\pi_{1}$ & $\pi_{2}$ \\
\hline$\pi_{1}$ & $n_{11}$ & $n_{12}$ \\
\hline$\pi_{2}$ & $n_{21}$ & $n_{22}$ \\
\hline
\end{tabular}

$n_{11}=$ jumlah pengamatan dari $\pi_{1}$ tepat diklasifikasikan sebagai $\pi_{1}$

$n_{12}=$ jumlah pengamatan dari $\pi_{1}$ tepat diklasifikasikan sebagai $\pi_{2}$

$n_{21}=$ jumlah pengamatan dari $\pi_{2}$ tepat diklasifikasikan sebagai $\pi_{1}$

$n_{22}=$ jumlah pengamatan dari $\pi_{2}$ tepat diklasifikasikan sebagai $\pi_{2}$

$$
A P E R=\left(\frac{n_{12}+n_{21}}{n_{11}+n_{12}+n_{21}+n_{22}}\right) \times 100 \%
$$

\subsection{Langkah Penyelesaian Nä̈ve Bayes}

Langkah-langkah penyelesaian pada metode Nä̈ve Bayes adalah sebagai berikut:

1) Bagi data menjadi 2 bagian, yaitu data Training dan data Testing

2) Bentuk model dengan Data Training, menurut Zhang J., et al. (2007), dalam memilih pembagian Data Training dan Data Testing dapat berdasarkan $90 \%$ berbanding 10\%, $80 \%$ berbanding 20\%, dan $70 \%$ berbanding 30\%. Dalam penelitian ini, perbandingan data Training dan data Testing yang digunakan sebesar $80 \%$ berbanding $20 \%$

3) Evaluasi seberapa tepat klasifikasi dilakukan dari Data Training dan Data Testing

4) Buatlah model klasifikasinya.

\subsection{Variabel Penelitian}

Variabel-variabel yang terlibat dalam penelitian ini adalah : 
a) Variabel Dependen

Variabel dependen dalam penelitian ini yaitu merk sepeda motor sebelumnya meliputi merk $\mathrm{T}$, merk $\mathrm{C}$, merk $\mathrm{B}$, merk $\mathrm{A}$, merk lain dan konsumen yang belum pernah memiliki sepeda motor. Variabel dependen untuk karakter Repeat Order yaitu konsumen dengan sepeda motor sebelumnya merk T. Sedangkan Variabel dependen untuk karakter New Customer yaitu konsumen dengan merk sepeda motor sebelumnya merk C, merk B, merk A.

b) Variabel independen pada penelitian ini terdiri dari tujuh variabel, yaitu:

1) $X_{1}$ merupakan jenis sepeda motor yang dibeli (Bebek, Automatic dan Sport)

2) $X_{2}$ merupakan pekerjaan konsumen yang diamati. Terdiri dari sebelas jenis yaitu, pegawai negeri, pegawai swasta, ojek, wiraswasta/pedagang, mahasiswa/ pelajar, guru/dosen, TNI/Polri, ibu rumah tangga, petani/nelayan, profesional (dokter/pengacara, dll), dan lain-lain.

3) $X_{3}$ merupakan besarnya pengeluaraan konsumen dalam satu bulan yang terdiri dari 13 jenis yaitu, <Rp.700.000, Rp. 600.001 s/d Rp. 900.000, Rp.700.001 s/d Rp.1.000.000, Rp.1.000.001 s/d Rp.1.500.000, Rp. 1.250.001 s/d Rp. 1.750.000, Rp. 1.500.001 s/d Rp. 2.000.000, Rp. 1.750.000 s/d Rp.2.000.000, Rp.2.000.001 s/d Rp.3.000.000, Rp.2.500.001 s/d Rp.3.500.000 Rp.3.000.001 s/d Rp.4.000.000, >Rp. 3.500.000, >Rp.4.000.000.

4) $X_{4}$ merupakan jenis sepeda motor sebelumnnya (bebek, automatic dan sport)

5) $X_{5}$ merupakan pemakai sepeda motor yang diamati. Terdiri dari empat jenis yaitu, saya sendiri, anak, pasangan (suami/ istri), dan lain-lain.

6) $X_{6}$ merupakan kota dimana konsumen membeli sepeda motor merk $\mathrm{T}$. Terdiri dari 18 kota yaitu, Bandung, Bekasi, Bogor, Ciamis, Cianjur, Cikarang, Cirebon, Depok, Garut, Indramayu, Karawang, Kuningan, 
Majalengka, Purwakarta, Subang, Sukabumi, Sumedang, dan Tasikmalaya.

7) $X_{7}$ merupakan tahun pembelian sepeda motor $(2011,2012$, dan 2013).

\section{HASIL DAN PEMBAHASAN}

\subsection{Hasil Klasifikasi}

Tabel 2. Karakteristik Konsumen Sepeda Motor Merk T di Jawa Barat

\begin{tabular}{|c|c|c|}
\hline \multirow{2}{*}{$\mathrm{T}$ Variabel } & \multicolumn{2}{|c|}{ Karakteristik Konsumen } \\
\cline { 2 - 3 } & New Customer & Repeat Order \\
\hline $\begin{array}{c}\text { Jenis Sepeda Motor } \\
\text { Yang Dibeli }\end{array}$ & AT (Automatic) & AT (Automatic) \\
\hline $\begin{array}{c}\text { Pekerjaaan Konsumen } \\
\text { Pegawai Swasta }\end{array}$ & $\begin{array}{c}\text { Pegawai Swasta dan } \\
\text { Wiraswasta/Pedagang }\end{array}$ \\
\hline $\begin{array}{c}\text { Pengeluaran Konsumen } \\
\text { Dalam Satu Bulan }\end{array}$ & $\begin{array}{c}\text { Rp. } 1.500 .001 \mathrm{~s} / \mathrm{d} \\
\text { Rp. } 2.000 .000\end{array}$ & $\begin{array}{c}\text { Rp. } 1.500 .001 \mathrm{~s} / \mathrm{d} \\
\text { Rp. } 2.000 .000\end{array}$ \\
\hline $\begin{array}{c}\text { Jenis Sepeda Motor } \\
\text { Sebelumnya }\end{array}$ & Belum Pernah Memiliki & CUB (Bebek) \\
\hline Pemakai Sepeda Motor & Sendiri & Sendiri \\
\hline Kota & Bekasi & Bekasi \\
\hline Tahun Pembelian & 2013 & 2013 \\
\hline
\end{tabular}

Tabel 2 menunjukkan hasil klasifikasi karakteristik konsumen New Customer sepeda motor merk $\mathrm{T}$ yaitu jenis sepeda motor yang dibeli adalah AT (Automatic), bekerja sebagai pegawai swasta, pengeluaran per-bulannya Rp. 1.500.001 s/d Rp. 2.000.000, sebelumnya tidak memiliki sepeda motor, sepeda motor yang dibeli untuk digunakan sendiri, berdomisili di kota Bekasi, membeli sepeda motor tersebut pada tahun 2013. Sebaliknya, klasifikasi karakteristik pada konsumen Repeat Order sepeda motor merk T yaitu jenis sepeda motor yang dibelinya adalah AT (Automatic), bekerja sebagai pegawai swasta atau wirausahawan/pedagang, pengeluaran per-bulannya Rp. 1.500 .001 s/d Rp. 2.000.000, sebelumnya memiliki sepeda motor berjenis CUB (Bebek), sepeda motor yang dibeli untuk digunakan sendiri, berdomisili di kota Bekasi, membeli sepeda motor tersebut pada tahun 2013.

Dari hasil klasifikasi karakteristik konsumen sepeda motor merk T di Jawa Barat tersebut terlihat bahwa sepeda motor dengan jenis AT (Automatic) sangat 
diminati oleh masyarakat dengan pengeluaran per-bulan Rp. 1.500.001 s/d Rp. 2.000.000 dan sepeda motor tersebut akan digunakan oleh sendiri. PT. JKL mencatat pada tahun 2013 penjualan tertinggi sepeda motor merk T di Jawa Barat terdapat di Kota Bekasi.

\subsection{Model Klasifikasi}

Model-model yang digunakan dalam penelitian ini adalah :

1) Model Klasifikasi New Customer (NC)

$$
\begin{aligned}
P\left(N C \mid X_{1}, X_{2}, \ldots, X_{7}\right)= & P\left(X_{1} \mid N C\right) \cdot P\left(X_{2} \mid N C\right) \cdot P\left(X_{3} \mid N C\right) \cdot P\left(X_{4} \mid N C\right) \\
& \cdot P\left(X_{5} \mid N C\right) \cdot P\left(X_{6} \mid N C\right) \cdot P\left(X_{7} \mid N C\right) \cdot P(N C)
\end{aligned}
$$

2) Model Klasifikasi Repeat Order (RO)

$$
\begin{aligned}
P\left(R O \mid X_{1}, X_{2}, \ldots, X_{7}\right)= & P\left(X_{1} \mid R O\right) \cdot P\left(X_{2} \mid R O\right) \cdot P\left(X_{3} \mid R O\right) \cdot P\left(X_{4} \mid R O\right) \\
& \cdot P\left(X_{5} \mid R O\right) \cdot P\left(X_{6} \mid R O\right) \cdot P\left(X_{7} \mid R O\right) \cdot P(R O)
\end{aligned}
$$

Peluang prior untuk konsumen dengan karakterisktik New Customer sebesar 0,634 dan peluang prior untuk konsumen dengan karakterisktik Repeat Order sebesar 0,365.

\subsection{Ketepatan Klasifikasi}

Tabel 3. Klasifikasi Untuk Actual Group dan Predicted Group

\begin{tabular}{|c|c|c|}
\hline \multirow{2}{*}{ Actual Group } & \multicolumn{2}{|c|}{ Predicted Group } \\
\cline { 2 - 3 } & New Customer & Repeat Order \\
\hline New Customer & 219752 & 68312 \\
\hline Repeat Order & 7850 & 158145 \\
\hline
\end{tabular}

$$
A P E R=\left(\frac{68312+7850}{219752+7850+68312+158145}\right)=0,167 \times 100 \%
$$

Hasil perhitungan APER menunjukkan bahwa kesalahan klasifikasi karakteristik New Customer dan Repeat Order konsumen sepeda motor merk T untuk data Testing sebesar $(0,167 \times 100 \%)=16,77 \%$ dengan ketepatan klasifikasi 
sebesar $(1-0.167) \times 100 \%=83,23 \%$. Hasil tersebut menunjukkan bahwa ketepatan klasifikasi pada penelitian ini cukup tinggi.

\section{KESIMPULAN DAN SARAN}

Dengan menggunakan metode Nä̈ve Bayes Classifier diperoleh peluang prior untuk konsumen dengan karakterisktik New Customer sebesar 0,634 dan peluang prior untuk konsumen dengan karakterisktik Repeat Order sebesar 0,365. Untuk pengklasifikasian karakteristik konsumen sepeda motor merk $T$ menunjukkan bahwa konsumen yang menggunakan sepeda motornya sendiri dan tidak pernah memiliki sepeda motor sebelumnya memiliki peluang lebih dari 0,65 untuk diklasifikasikan sebagai konsumen dengan karakteristik New Customer. Sedangkan untuk konsumen yang membeli sepeda motor merk $\mathrm{T}$ jenis AT (Automatic), pernah memiliki sepeda motor jenis CUB (Bebek), dan menggunakan sepeda motornya sendiri memiliki peluang di atas 0,65 untuk diklasifikasikan sebagai konsumen dengan karakteristik Repeat Order. Hasil pengklasifikasian tersebut memiliki kekeliruan klasifikasi sebesar 0,167.

Berdasarkan hasil evaluasi yang telah dilakukan pada penelitian ini, peneliti mengemukakan beberapa saran sebagai berikut:

1) Keberhasilan dari suatu penelitian data mining sangat bergantung kepada database. Artinya knowledge discovery dari penelitian Data Mining dilandasi oleh tidak hanya kualitas dan kuantitas data tetapi juga berbagai format yang digunakan (Olson dan Shi, 2007). Penulis menyarankan khususnya di dunia bisnis atau industri, pembangunan database betul-betul dirancang sedemikian rupa sehingga memudahkan untuk ditindaklanjuti oleh aplikasi Data Mining.

2) Agar memperoleh hasil klasifikasi yang lebih mendetail penulis menyarankan untuk menambahkan variabel prediktor pada penelitian selanjutnya.

\section{DAFTAR PUSTAKA}

Berson A., Smith, S.J., dan Thearling, K. Building Data Mining Applications for CRM (1st Edition), USA: McGraw-Hill Companies, Inc., 2001. 
Domingos, P. dan Pazzani, M., On the Optimality of the Simple Bayesian Clasifier Under Zero-one loss, Machine Learning, 1997.

Giudici, P., Applied Data Mining: Statistical Methods for Business and Industry, 2003.

Hair, J. F., Multivariate Data Analysis, Prentice Hall, Upper Saddle River, N. J., 1998.

Mitchell, T. M., Machine Learning, McGraw-Hill Companies, Inc., USA, 2010.

Novita, E., Penerapan Analisis Sentimen Dengan Metode Nä̈ve Bayes pada Klasifikasi Data Teks, Skripsi, Departemen Statistika FMIPA Universitas Padjadjaran, Bandung, 2014.

Olson, D. and Shi, Y., Introduction to Business Data Mining. McGraw-Hill Companies Inc., Singapore., 2007.

Zhang, Y.-C., Rossow, W.B., Stackhouse, P. W., Romanou, A., dan Wielicki, B. A., Decadal Variations of Global Energy and Ocean Heat Budget and Meridional Energy Transports Inferred from Recent Global Data Sets, J. Geophys. Res., D22101, 2010.

Zulhanif. Analisis Credit Scoring dengan Bayesian Klasifikasi, Prosiding Seminar Nasional Statistika : Peranan Statistika di Bidang Pemasaran dalam Penyusunan Strategi Bisnis, Universitas Padjadjaran, Bandung, 2012. 